\title{
Absence of Brain Antibodies in Patients with Schizophrenia*
}

\author{
SENGA WHITTINGHAM, † M.B., CH.B., D.C.P. ; IAN R. MACKAY, 9 M.D., M.R.C.P., F.R.A.C.P. \\ I. H. JONES, § M.D., M.R.C.P.ED., D.P.M., M.A.N.Z.C.P. ; BRIAN DAVIES, || M.D., M.R.C.P., D.P.M., D.C.H., M.A.N.Z.C.P.
}

Brit. med. F., 1968, 1, 347-348

In recent years the recognition of autoimmune processes has led to important advances in our understanding of certain diseases of hitherto uncertain causation (Mackay and Burnet, 1962). Burch (1964) postulated an autoimmune origin for schizophrenia on theoretical grounds from a study of the ageand sex-specific rates of first admissions to psychiatric hospitals. Heath and Krupp (1967) used immunofluorescence to study sections of brain and serum of schizophrenic patients; they found that globulin, presumably antibody, had become attached to nuclei of certain cells of the brain in vivo, and this antibody was also present in the serum. The claims that autoimmunity is concerned in schizophrenia have been cautiously appraised (Brit. med. F., 1967; Lancet, 1967). The present study describes an unsuccessful attempt to demonstrate antibodies to brain cells in schizophrenia.

\section{Materials and Methods}

\section{Patients}

We examined the brains of three patients with chronic schizophrenia and tested the serum of 13 patients with acute schizophrenia (eight males and five females) and 40 males with chronic schizophrenia.

The patients with acute schizophrenia were under the care of the University Department of Psychiatry (B. D. and I. H. J.) in short-stay beds ; the symptoms had been severe, and in most cases were present for only a few weeks or months before admission. The patients with chronic schizophrenia had been in a Victorian mental hospital for at least 10 years. Our criteria for diagnosis of schizophrenia were as follows: the establishment, either from a clear description in the clinical notes or from interview, of passivity feelings or a primary delusion. When neither of these symptoms was present a patient who showed at least four of the following five symptoms was diagnosed as a case of schizophrenia: (1) presence of delusions of elaboration; (2) presence of schizophrenic thought disorder; (3) presence of hallucinations; (4) flexibilitas cerea, catatonic episodes, or stereotypies ; (5) ideas of reference.

In the Venables (1957) Activity Withdrawal Scale the patients with chronic schizophrenia showed less than the normal amount of activity. We excluded patients with brain damage or mental deficiency and those who had previously had a leucotomy. No patient was receiving drugs.

Sera from 53 healthy subjects matched for age and sex with the patients were used as controls.

\section{Tissues and Antisera}

Brains were obtained from three patients with chronic schizophrenia (who had died with cancer not affecting the nervous system) and one from a control without schizophrenia. These were dissected within seven hours of death and tested within 24 hours of death. Cubes of tissue $2 \mathrm{~mm}$. in size were excised from the septal region, caudate nucleus, cerebellum, and cortex as described by Heath and Krupp (1967), and were snap-frozen either in a bath of solidified carbon dioxide and isopentane or on a strip of filter paper in a closed glass tube in a bath of solidified carbon dioxide and ethanol. The tissue was kept at $-70^{\circ} \mathrm{C}$. until sectioned at $4 \mu$ in a cryostat at $-20^{\circ} \mathrm{C}$. Two sections were prepared: one was air-dried and the other was fixed for 30 seconds in $95 \%$ ethanol in a bath of solidified carbon dioxide and isopentane. Other tissues used were rat liver and human peripheral blood smears fixed in ethanol (Smalley et al., 1968), unfixed thyroid gland from a patient with thyrotoxicosis of blood group $\mathrm{O}$, and unfixed rat stomach (Holborow et al., 1959 ; De Boer et al., 1965).

The brains of the three patients studied and the thymus glands of two were examined microscopically after routine histological processing.

Antihuman immunoglobulins $G$ and $A$ were prepared by injecting rabbits with $2.5 \mathrm{mg}$. of immunoglobulin in $0.5 \mathrm{ml}$. of saline and $1 \mathrm{ml}$. of Freund's complete adjuvant: $0.1 \mathrm{ml}$. was injected intradermally into the footpads, back, and flanks. The rabbits were injected 30 days later with the same amount of globulin in Freund's incomplete adjuvant and bled two weeks later. The immunoglobulin $G$ fraction of rabbit serum containing antibody was isolated and conjugated with fluorescein isothiocyanate (Wood et al., 1965). Rabbit antihuman immunoglobulin $M$ conjugated with fluorescein (Batch No. F 211D) was donated by Australian Hoechst Ltd.

\section{Immunofluorescence Tests}

In testing for globulins bound in vivo to the brain of schizophrenic patients frozen sections of brain were washed in six changes of phosphate-buffered saline $p H 7.3$ incubated at $37^{\circ}$ C. for 30 minutes with antihuman globulin conjugated with fluorescein, washed in two changes of phosphate-buffered saline and mounted in $10 \%$ phosphate-buffered saline in glycerol. The various preparations were examined under a Leitz microscope fitted with a source of ultraviolet light. Light of two wavelengths was used: one was obtained by a BG 12 transmission filter and OG 1 suppression filter, and the other by a UG 1 transmission filter and a K 430 suppression filter. A BG 38 filter eliminated red light.

The same immunofluorescence procedure was used when testing for antibody in serum except that tissue was incubated with serum at $37^{\circ} \mathrm{C}$. for 30 minutes and washed in two changes of phosphate-buffered saline before applying antihuman globulin.

\section{Results}

Brains of Schizophrenic Patients.-None of the three brains obtained from patients with chronic schizophrenia showed globulin bound to brain cells in any of the regions examined

* Publication No. 1224, Walter and Eliza Hall Institute of Medical Research, the Royal Melbourne Hospital, Melbourne, Australia.

+ Serologist to the Clinical Research Unit, Walter and Eliza Hall Institute of Medical Research.

$\ddagger$ Head of the Clinical Research Unit, Walter and Eliza Hall Institute of Medical Research.

First Assistant to Department of Psychiatry, University of Melbourne and the Royal Melbourne Hospital, Victoria, Australia.

II Cato Professor of Psychiatry, University of Melbourne and the Royal Melbourne Hospital, Melbourne, Australia.

I Working with the aid of a grant from the National Health and Medical Research Council of Australia. 
(see methods). These three brains showed no abnormal histological features on light microscopy.

Serum of Schizophrenic Patients (see Table).-Of the 13 sera from patients with acute schizophrenia none reacted with nuclei of brain cells from different regions of brain obtained from schizophrenic and non-schizophrenic patients, nor with nuclei from other tissues. Of the 40 sera from patients with chronic schizophrenia, four reacted, three strongly and one weakly, with nuclei of brain cells in the septal region, caudate nucleus, cerebellum, and cortex of schizophrenic and nonschizophrenic brain, and with the nuclei of cells in other tissues - that is, these sera contained the usual widely reactive antinuclear factor. The serum of one patient with acute schizophrenia reacted weakly with cytoplasm of thyroid epithelial cells. The serum of one patient with chronic schizophrenia reacted weakly with cytoplasm of thyroid epithelial cells and the serum of two patients with cytoplasm (microsomes) of gastric parietal cells. All the serological reactions given by the patients with schizophrenia had an incidence similar to that obtained with the matched healthy subjects. The histories given by the four schizophrenic patients with antinuclear reactions were typical and these patients showed no remarkable clinical features ; in particular there was no evidence of systemic lupus erythematosus or allied disorder.

Thymus.-The thymuses of two schizophrenic patients from whom brain was obtained for testing were histologically normal for the patient's age.

Incidence in Schizophrenia of Serum Antibodies Reacting by Immunofluorescence with Nuclei of Brain Cells of Schizophrenic and "Normal" Subjects and With Other Antigens

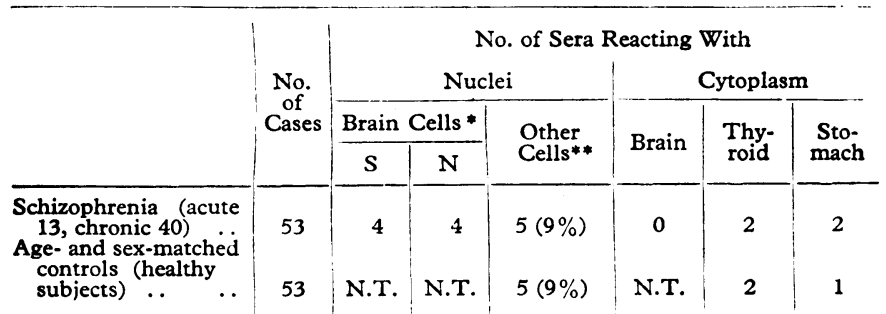

$* \mathrm{~S}=$ Schizophrenic brain $(3$ tested). $\mathrm{N}=$ Non-schizophrenic brain. N.T. $=$ Not Tested.

\section{Discussion}

Patients with schizophrenia are claimed to have abnormal serum proteins of antibody character (Heath et al., 1957-8; Fessel, 1962 ; Kopeloff and Fischel, 1963 ; Sapira, 1964). These proteins injected into rat and monkey produced changes in behaviour of the animals (Bergen et al., 1963 ; Bishop, 1963 ; Ferguson and Fisher, 1963 ; Heath et al., 1967), though these findings were not corroborated by Sanders et al. (1965). Kuznetsova and Semenov (1961) found a high incidence of complement-fixing anti-brain antibodies in serum of patients with schizophrenia and with psychosis, but their findings were not confirmed by Fessel (1963) or Rubin (1965).

The need to assess further autoimmune serological reactions in patients with schizophrenia became evident when Burch (1964) proposed that schizophrenia was an autoimmune disease ; he developed his theory on the age-specific and sex-specific incidence rates of schizophrenia when patients were first admitted to hospital. Heath et al. (1957-8) had isolated from the serum of patients with schizophrenia an abnormal protein taraxein which produced electroencephalographic changes when injected into monkeys. Later Heath and Krupp (1967) claimed that serum of schizophrenic patients contained a protein identified as immunoglobulin $G$ which behaved like an autoantibody in binding to cell nuclei in the septal and caudate nuclear regions of the brain. It became bound in vivo to the brain cell nuclei of schizophrenic patients, and in vitro it reacted strongly with brain cell nuclei of patients with schizophrenia but poorly if at all with brain cell nuclei of normal subjects.
Certain aspects of Heath's studies warrant special reference. Firstly, he laid more emphasis on the in-vivo binding of globulin to brain cell nuclei, demonstrable in 14 out of 16 brains from schizophrenic patients; we could not demonstrate this but examined brains from only three patients with chronic schizophrenia. Secondly, there has been no previous description of an autoantibody with specificity for the nuclei (rather than the cytoplasm) of the presumed target organ ; in fact, tissue specificity of antinuclear antibody is unusual though it does occur (Faber and Elling, 1967). Thirdly, Heath and Krupp (1967) found that "schizophrenic serum" reacted more strongly with "schizophrenic brain" than with " non-schizophrenic brain"; we know of no situation wherein tissue which is functionally but not histologically abnormal differs antigenically from the corresponding normal tissue. The antinuclear factor present in the serum of 4 of the 53 patients in our series was of the "usual" type, and the incidence was the same as that in controls.

Schizophrenia does not fulfil any of the conventional " markers" for an autoimmune disorder (Mackay and Burnet, 1962 ; Asherson, 1967), and at present we cannot confirm that antibody specifically directed against brain cell nuclei is present in the serum of schizophrenic patients. None the less we would not wish our findings to discourage others from examining further the possibility that autoimmunity is concerned in the pathogenesis of schizophrenia.

\section{Summary}

Recent discussions on autoimmunity as a cause of schizophrenia led us to examine by immunofluorescence three brains from patients with chronic schizophrenia and serum from 53 patients with acute or chronic schizophrenia and 53 normal controls. In contrast to Heath et al. (1967) we could not show that globulin became bound in vivo to nuclei of brain cells of schizophrenic patients nor could we show that the incidence of serum antibody against brain cell nuclei was greater in schizophrenic patients than in controls.

We thank Dr. S. Weiner, Pathologist to the Mental Health Authority, Dr. J. D. Hicks, Pathologist to the Royal Melbourne Hospital, Dr. T. Pearce, Mont Park Mental Hospital, and Dr. A. Stoller, Chief Clinical Officer, Mental Health Authority, for their generous co-operation. Dr. R. Anderson and Dr. G. Robson gave guidance with the dissection of brains. We thank Miss J. Irwin for her expert technical assistance.

\section{REFERENCES}

Asherson, G. L. (1967). Brit. med. f., 3, 479. . Serological Fractions in Schizophrenia, edited by R. G. Heath, p. 67. New York.

Bishop, M. P. (1963). Ibid., p. 77.

Brit. med. F., 1967, 3, 569.

Burch, P. R. J. (1964). Brit. F. Psychiat., 110, 818.

De Boer, W. G. R. M., Nairn, R. C., and Maxwell, A. (1965). F. clin. Path., 18, 456 .

Faber, V., and Elling, P. (1967). Acta path. microbiol. scand., 69, 11.

Ferguson, D. C., and Fisher, A. E. (1963). Science, 139, 1281.

Fessel, W. J. (1962). Arch. gen. Psychiat., 6, 320.

Fessel, W. J. (1963). Ibid., 8, 614 .

Heath, R. G., and Krupp, I. M. (1967). Ibid., 16, 1

- Byers, L. W., and Liljekvist, J. I. (1967). Ibid., 16, 10.

- Martens, S., Leach, B. E., Cohen, M., and Feigley, C. A. (1957-8). Amer. F. Psychiat., 114, 917.

Holborow, E. J., Brown, P. C., Roitt, I. M., and Doniach, D. (1959). Brit. F. exp.' Path., 40, 583.

Kopeloff, L. M., and Fischel, E. (1963). Arch. gen. Psychiat., 9, 524.

Kuznetsova, N. I., and Semenov, S. F. (1961). Zh. Nevropat. Psikhiat.,

61, 869.
Lancet, 1967, 1, 828.

Mackay, I. R., and Burnet, F. M. (1962). Autoimmune Diseases : Pathogenesis, Chemistry, and Therapy, p. 16. Springfield, Illinois.

Rubin, R. T. (1965). Brit. 7. Psychiat., 111, 1003.

Sanders, B. E., Small, S. M., Ayers, W. J., Oh, Y. H., and Axelrod, S. (1965). Trans. N.Y. Acad. Sci., 28, 22.

Sapira, J. D. (1964). Arch. gen. Psychiat., 10, 196.

Smalley, M. J., Mackay, I. R., and Whittingham, S. (1968). Aust. Ann. Med. In press.

Venables, P. H. (1957). f. ment. Sci., 103, 197.

Wood, B. T., Thompson, S. H., and Goldstein, G. (1965). F. Immunol., 95, 225 . 